\title{
Left Ventricular Non-Compaction Syndrome
}

National Cancer Institute

\section{Source}

National Cancer Institute. Left Ventricular Non-Compaction Syndrome. NCI Thesaurus.

Code C99544.

An uncommon congenital abnormality where the left ventricular myocardium fails to compact during embryonic development, leading to cardiomyopathy with a variable degree of ventricular dysfunction. There is genetic heterogeneity and phenotypic variability. Characteristically, there are typically deep trabeculations in the noncompacted area, with varying proportions of the LV myocardium compacted. LV noncompaction is associated with rhythm abnormalities including Wolff-Parkinson-White syndrome, conduction defects, and ventricular tachyarrhythmias. 